\title{
INDIRECT ESTIMATION OF THE STEP LENGTH OF WALKING AND RUNNING PERFORMANCES ON THE TREADMILL
}

\section{R. Vinodh Rajkumar.}

Physiotherapist \& Anthropologist. Director - Prabhanjeet Fitness Research Institute OPC Private Limited. Bangalore, Karnataka, India.

\section{ABSTRACT}

Introduction: Cadence and step length are important biomechanical variables of walking and running but they are not typically monitored by the treadmills. This study explains a novel non-invasive method to estimate the step length of walking and running to maximize the professional skills and scientific capabilities of Physiotherapists and Exercise professionals.

Methodology: Seventeen individuals (10 men and 7 women) who have been undergoing supervised fitness training programs were selected for the biomechanical analysis of the relationship between cadence and step length of walking and running on the treadmill in the speeds ranging from $5 \mathrm{Km} / \mathrm{h}$ to $15 \mathrm{Km} / \mathrm{h}$ for men and $5 \mathrm{Km} /$ $\mathrm{h}$ to $12 \mathrm{Km} / \mathrm{h}$ for women.

Results: Exercisers displayed wide range of step length strategies to manage the walking and running speeds opted for the experiment. Additionally, when the same exercisers were allowed to exhibit their maximum running speed in the outdoor environment, a statistically significant difference was found because all of them faced psychological constraints to explore or sustain their fastest running ability on the treadmill.

Conclusion: Assessment of cadence and step lengths of the patients and exercisers looks indispensable. Visual counting method to calculate the cadence can be easily acquired through practice, usually accompanied by the development of the skill to compute the step lengths using mathematical formulae. The same method can be used to ascertain if the individuals are adapting symmetrical or asymmetrical step lengths by just separately counting the number of steps produced by each lower extremity for a specific time length ( 30 seconds or 60 seconds). Experts should continue exploring such feasible, non-invasive and inexpensive diagnostic procedures.

KEY WORDS: Treadmill, Cadence, Step length, Gait, Running, Sprinting, Stride frequency.

Address for correspondence: R. Vinodh Rajkumar, Physiotherapist \& Anthropologist, Director Prabhanjeet Fitness Research Institute OPC Private Limited, Bangalore, Karnataka, India.

E-Mail: dreamofkalam@rediffmail.com

\section{Access this Article online}

Quick Response code

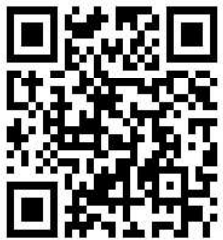

DOI: $10.16965 /$ ijpr.2020.110
Journal Information

International Journal of Physiotherapy and Research ISSN (E) 2321-1822 | ISSN (P) 2321-8975 https://www.ijmhr.org/ijpr.html DOI-Prefix: https://dx.doi.org/10.16965/ijpr (cc) $\mathrm{ET}-\mathrm{NC}-\mathrm{BA}$
Received: 17 Feb 2020

Peer Review: 17 Feb 2020

Revised: None

Article Information

\section{INTRODUCTION}

Healthy ageing endeavors chiefly revolve around rectification of biomechanical errors and preservation of biomechanical efficiency of the body for sustainable survival competence and functional independence. Based on this awareness, it is well known that there has been enthusiasm shown by people all over the globe to especially avail the indoor exercise facilities in fitness clubs and at their luxury residences. Recently, Physiotherapists in India also have begun to install various exercise machineries in their clinics, apart from the customary electrotherapy treatment apparatuses, to support their treatment procedures. One of the inevitable exercise devices in the indoor exercise settings 
has been treadmill that has attracted so many people. Though treadmill has been a replacement for lack of outdoor exercise facility or for those who perceive outdoor as inconvenient for walking and running, many of them have been using this equipment counter-productively (holding the rails of treadmill, selecting inappropriate exercise dosage, not having objectively measurable goals). But quite a lot of information about the exercise tolerance, cardiorespiratory endurance, postural deviations of the patients and exercisers could be derived by non-invasively testing their locomotion on the treadmill. Treadmills generally display the variables like speed, distance, calorie expenditure, time and gradient to guide the professionals and exercisers to select appropriate exercise targets. Cadence (stride frequency) and step length are important biomechanical variables of walking and running but they are typically not monitored by the treadmills. To certain extent, without the need of specialized equipment, some biomechanical analyses can also be done just by visual observations and non-participant observation to decode the kinetics of various static and dynamic postures [1]. This study explains a novel non-invasive method to estimate the step length of walking and running to maximize the scientific capabilities of Physiotherapists to benefit their patients and clientele visiting their exercise or rehabilitation units.

\section{METHODOLOGY}

Table 1: Age range for men $=35-51$ years. Age range for women $=33-46$ years. Lower limb length was measured from greater trochanter of femur to heel using an inch tape.

\begin{tabular}{|c|c|c|}
\hline & Men $(\mathbf{n}=\mathbf{1 0})$ & Women $(\mathbf{n}=\mathbf{7})$ \\
\hline Weight & $\begin{array}{c}\text { Range }=70-95 \mathrm{Kg} \\
\text { Mean }=77.6 \mathrm{Kg}\end{array}$ & $\begin{array}{c}\text { Range }=52-73 \mathrm{Kg} \\
\text { Mean }=62.8 \mathrm{Kg}\end{array}$ \\
\hline Height & $\begin{array}{c}\text { Range }=165-179 \mathrm{~cm} \\
\text { Mean }=171.5 \mathrm{~cm}\end{array}$ & $\begin{array}{c}\text { Range }=153-174 \mathrm{~cm} \\
\text { Mean }=162.8 \mathrm{~cm}\end{array}$ \\
\hline Fat \% & $\begin{array}{c}\text { Range }=22-35 \% \\
\text { Mean }=30 \%\end{array}$ & $\begin{array}{c}\text { Range }=29-42 \% \\
\text { Mean }=35.8 \%\end{array}$ \\
\hline Lower limb length & $\begin{array}{c}\text { Range }=83-95 \mathrm{~cm} \\
\text { Mean }=89.8 \mathrm{~cm}\end{array}$ & $\begin{array}{c}\text { Range }=78-94 \mathrm{~cm} \\
\text { Mean }=84.5 \mathrm{~cm}\end{array}$ \\
\hline
\end{tabular}

As shown in Table-1, 10 men and 7 women who have been undergoing supervised fitness training programs were selected for the biomechanical analysis of the relationship between cadence and step length of walking and running on the treadmill in the speeds ranging from $5 \mathrm{Km} \mathrm{h}$ to $15 \mathrm{Km} / \mathrm{h}$ for men $(5,7.5,10,12.5$ and
$15 \mathrm{Km} / \mathrm{h}$ ) and $5 \mathrm{Km} / \mathrm{h}$ to $12 \mathrm{Km} / \mathrm{h}$ for women $(5,7.5,10$ and $12 \mathrm{Km} / \mathrm{h})$.

The maximum speed of $15 \mathrm{Km} / \mathrm{h}$ for men and 12 $\mathrm{Km} / \mathrm{h}$ for women were opted based on the empirical knowledge that most of the nonathlete population seldom opt speeds higher than these speeds and in fact, some of these exercisers had to be strongly motivated to tolerate the exercise stress while running at higher speeds on the treadmill just for 30 to 60 seconds. The cadence of walking and running for the selected speeds were visually counted for 15 seconds at least twice by observing the foot placements. On the treadmill, the walking and running steps can be also heard, so the auditory signals were also adjoining the visual counting method to enhance the precision. It was also decided to examine the maximum running speed of all these exercisers in the outdoor setting on the level ground and compare this outdoor sprinting performance with their maximum speed performance on the treadmill. All the selected exercisers were informed that the walking and running at different speeds are part of their exercise activity and they were entirely unaware of the ongoing cadence assessment. Step length on treadmill (SLt) was indirectly measured in centimeters using the formula;

$$
\mathrm{SLt}=\left(\frac{\text { Speed in } \mathrm{Km} / \mathrm{h}}{60 \times \text { Cadence }}\right) \times 10^{5}
$$

For example, if the cadence of an individual walking at $5 \mathrm{Km} / \mathrm{h}$ was 120 steps per minute, then the SLt will equal $69.4 \mathrm{~cm}$ (based on this formula). Due to lack of athletic track facility, 28 meters length of the basket ball court in the residential apartment of the exercisers was used to test their maximum running speed in outdoor settings. Maximum running speed performed on the 28 meters level ground can be calculated using the formula;

$$
\operatorname{SPEED}(\mathrm{Km} / \mathrm{h})=\frac{3600 \times 0.028}{\text { Time taken }}
$$

For example, if the time taken to reach 28 meters is 5.2 seconds, then the running speed equals $19.38 \mathrm{Km} / \mathrm{h}$. Step length of 28 meters run performed outdoor or over-ground (SLo) can be derived by the formula;

$$
\text { SLo }=\left(\frac{28 \text { meters }}{\text { Total running steps }}\right) \times 100
$$


For example, if the total number of running steps of an individual to reach 28 meters is 18 , then the SLo equals $155 \mathrm{~cm}$ (based on this formula).

\section{RESULT}

Table 2: SLt of Men ( $n=10)$ at different speeds.

\begin{tabular}{|c|c|c|c|c|c|}
\hline & $5 \mathrm{Km} / \mathrm{h}$ & $7.5 \mathrm{Km} / \mathrm{h}$ & $10 \mathrm{Km} / \mathrm{h}$ & $12.5 \mathrm{Km} / \mathrm{h}$ & $15 \mathrm{Km} / \mathrm{h}$ \\
\hline Range $(\mathrm{cm})$ & $67-77$ & $84-95$ & $89-107$ & $111-133$ & $125-152$ \\
\hline Mean (cm) & 71.3 & 89.7 & 101.4 & 120.9 & 134.5 \\
\hline
\end{tabular}

Table 3: SLt of Men ( $n=10)$ at different speeds.

\begin{tabular}{|l|c|c|c|c|}
\hline & $4 \mathrm{Km} / \mathrm{h}$ & $6 \mathrm{Km} / \mathrm{h}$ & $8 \mathrm{Km} / \mathrm{h}$ & $12 \mathrm{Km} / \mathrm{h}$ \\
\hline Range (cm) & $57-67$ & $73-86$ & $76-98$ & $106-131$ \\
\hline Mean (cm) & 63.5 & 80.3 & 87 & 116 \\
\hline
\end{tabular}

Table 4: SLt of Women $(n=7)$ at different speeds.

\begin{tabular}{|c|c|c|c|}
\hline & $4 \mathrm{Km} / \mathrm{h}$ & $6 \mathrm{Km} / \mathrm{h}$ & $8 \mathrm{Km} / \mathrm{h}$ \\
\hline Range $(\mathrm{cm})$ & $57-62$ & $73-81$ & $79-83$ \\
\hline Mean $(\mathrm{cm})$ & 59.3 & 76.6 & 81.3 \\
\hline
\end{tabular}

Table 5: SLt of Women $(n=7)$ at different speeds. One woman was excluded from $12 \mathrm{Km} / \mathrm{h}$ exposure due to her low exercise tolerance. Therefore, only 6 women were tested for $12 \mathrm{Km} / \mathrm{h}$ on the treadmill.

\begin{tabular}{|c|c|c|c|c|}
\hline & $5 \mathrm{Km} / \mathrm{h}$ & $7.5 \mathrm{Km} / \mathrm{h}$ & $10 \mathrm{Km} / \mathrm{h}$ & $12 \mathrm{Km} / \mathrm{h}$ \\
\hline Range $(\mathrm{cm})$ & $67-72$ & $76-87$ & $90-100$ & $106-113$ \\
\hline Mean (cm) & 70 & 80.3 & 95.2 & 108 \\
\hline
\end{tabular}

Table 6: SLo of Men ( $n=10)$ and Women $(n=6)$. One woman (in fact the same woman who was excluded from $12 \mathrm{Km} /$ $h$ exposure on treadmill as discussed in Table -5) was excluded from this statistical analysis and paired-t test too. Interestingly, though she was not confident to run at $12 \mathrm{Km} / \mathrm{h}$ to run on the treadmill, she could run at 12.8 $\mathrm{Km} / \mathrm{h}$ in 28 meters outdoor test for maximum running speed. Her fitness characteristics are shown in Table -9 as Female B.

\begin{tabular}{|c|c|c|}
\hline & Men & Women \\
\hline \multirow{2}{*}{ Speed } & $\begin{array}{c}\text { Range: } 17.7-21.4 \mathrm{Km} / \mathrm{h} \\
\text { Mean: } 19.1 \mathrm{Km} / \mathrm{h}\end{array}$ & $\begin{array}{c}\text { Range: } 12.9-21 \mathrm{Km} / \mathrm{h} \\
\text { Mean: } 15.8 \mathrm{Km} / \mathrm{h}\end{array}$ \\
\hline \multirow{2}{*}{ Step length } & $\begin{array}{c}\text { Range: } 133-155 \mathrm{~cm} \\
\text { Mean: } 141 \mathrm{~cm}\end{array}$ & $\begin{array}{c}\text { Range: } 107-150 \mathrm{~cm} \\
\text { Mean: } 127 \mathrm{~cm}\end{array}$ \\
\hline
\end{tabular}

Table 7: Paired t-test (Maximum step length on treadmill versus over-ground).

\begin{tabular}{|c|c|}
\hline $\begin{array}{c}\text { Calculated t value for men } \\
(n=10)\end{array}$ & $\begin{array}{c}2.76 \\
\text { (tabulated t value at 5\% level } \\
\text { of significance }=1.833)\end{array}$ \\
\hline $\begin{array}{c}\text { Calculated t value for women } \\
(n=6)\end{array}$ & $\begin{array}{c}3.38 \\
\text { (tabulated t value at } 5 \% \text { level } \\
\text { of significance = 2.01) }\end{array}$ \\
\hline
\end{tabular}

Table 2 to 7 summarizes the data of step length computed based on the formula of SLt and SLo, inputting the observed cadence. Step length (SLt and SLo) indicates the distance covered per step in centimeters. To understand the dynamics in SLt when the speed increases 2 or 3 times more, some additional tests were also performed using the speeds $4 \mathrm{Km} / \mathrm{h}, 6 \mathrm{Km} / \mathrm{h}, 8 \mathrm{Km} / \mathrm{h}$ for both men and women. Closer look at these tables could reveal near-doubling of the SLt as the speed increases three times more. For example, the mean SLt for men at $5 \mathrm{Km} / \mathrm{h}$ and $15 \mathrm{Km} / \mathrm{h}$ was $71.3 \mathrm{~cm}$ and $134.5 \mathrm{~cm}$, respectively and such interesting relationships were found at the individual level in some exercisers also, which needs more detailed studies in the future to expand the gait science.

\section{DISCUSSION}

Table 8: Varying cadences of a 30 years old female attributable to her Quadriceps muscle soreness during the initial assessment. (Weight $=54 \mathrm{Kg}$, Height $=158 \mathrm{~cm}$, Fat $\%=30$, Lower limb length $=80 \mathrm{~cm}$ ).

\begin{tabular}{|c|c|c|}
\hline Speed & $\begin{array}{c}\text { Cadence and SLt } \\
\text { (Initial) }\end{array}$ & $\begin{array}{c}\text { Cadence and SLt } \\
\text { (ten days later) }\end{array}$ \\
\hline $\mathbf{8 ~ K m} / \mathbf{h}$ & $\begin{array}{l}168 \text { steps per minute } \\
\text { Step length }=79.3 \mathrm{~cm}\end{array}$ & $\begin{array}{l}162 \text { steps per minute } \\
\text { Step length }=82.3 \mathrm{~cm}\end{array}$ \\
\hline $10 \mathrm{Km} / \mathrm{h}$ & $\begin{array}{l}180 \text { steps per minute } \\
\text { Step length }=92.6 \mathrm{~cm}\end{array}$ & $\begin{array}{l}172 \text { steps per minute } \\
\text { Step length }=97 \mathrm{~cm}\end{array}$ \\
\hline $12 \mathrm{Km} / \mathrm{h}$ & $\begin{array}{l}188 \text { steps per minute } \\
\text { Step length }=106 \mathrm{~cm}\end{array}$ & $\begin{array}{l}178 \text { steps per minute } \\
\text { Step length }=112 \mathrm{~cm}\end{array}$ \\
\hline
\end{tabular}

As the speed of locomotion increased from walking to running, concomitant increase in the cadence and step length were noticed in both men and women, in the speed ranges opted for the analyses. The inter-individual differences in the cadence and step length could be due to various variables like limb length, fat percentage, body weight, fitness level, the extent of running exposures to higher speeds on treadmill and over-ground etc. There was consistent evidence that increased stride rate (reduced stride length) resulted in decreased center of mass vertical excursion, ground reaction force, shock attenuation, and energy absorbed at the hip, knee, and ankle joints, to reduce the magnitude of several key biomechanical factors associated with running injuries [2]. Individuals might display different cadence for a particular speed on the same day or in the future. Table 8 shows the varying cadence of a woman when measured again after ten days to evaluate its consistency. She displayed such differences in cadence and step length probably because during the first assessment she had reported bilateral Quadriceps muscle soreness that was absent while measuring the cadence ten days 
later. Perhaps increasing the cadence during the day of muscle soreness was her innate strategy to manipulate the cadence for reducing the work load of her sore Quadriceps or reducing the injury risks or both.

Substantial reduction in energy absorption occurs at the hip and the knee when step rate is increased to $10 \%$ above preferred with a constant running speed, whereas a $5 \%$ increase appears to reduce the total work performed by the knee, thus the reduction in joint loading via step rate manipulation may have distinct benefits in the treatment and prevention of common running-related injuries involving the knee and the hip [3]. Physiotherapists can expect such variations in the cadence and step length of their clientele and try to correlate them with all other data collected during the assessments and confirm if they are the favourable or unfavourable signs of ongoing rehabilitation or strength and conditioning program. Improvements in stride analysis also correlate with improvements in a person's functional ambulation [4]. Over time, changes in stride length may occur but at any point of the spectrum from inexperienced to experienced, the chosen stride length is probably ideal for economy [5]. Figure 1 shows the progression in 12 minutes run test performance of a male (46 years) over a period of 6 months and his transformation in step length strategies to maximize the performance.

Figure 1: 46 years old male with improvements in 12 minutes run test (Cooper's test) on the treadmill and, the step length and cadence strategy used by him as the speed level got changed. In one year, he displayed a fluctuating body weight and body composition (Body weight $=81-83 \mathrm{Kg}$, Fat $\%=29-33$, Fat mass $=23.5-$ $27.5 \mathrm{Kg}$ and Lean mass $=55.5-57.5 \mathrm{Kg}$ ). His sprinting pace was $18.7 \mathrm{Km} / \mathrm{h}$ in 28 meters test in outdoor settings, with a step length of $140 \mathrm{~cm}$.

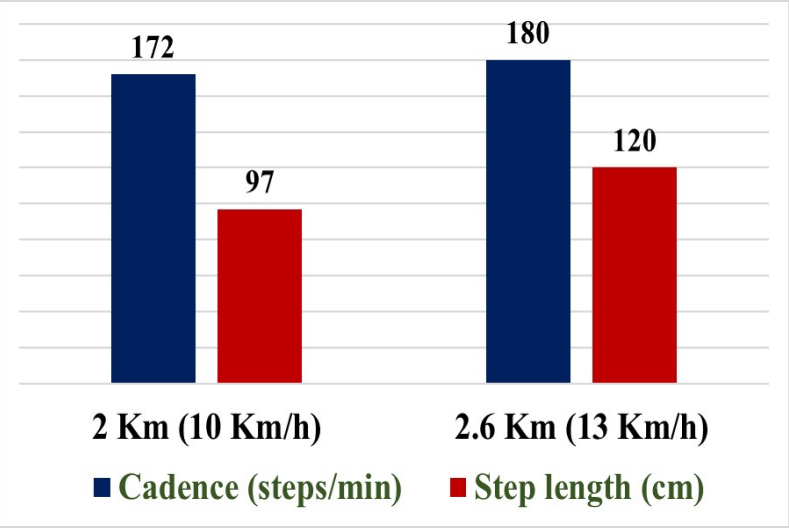

Stride frequency (SF) or Step length (SL) reliance is a highly individual occurrence and it is proposed that athletes should take this reliance into account in their training, with SF-reliant athletes needing to keep their neural system ready for fast leg turnover and SL-reliant athletes requiring more concentration on maintaining strength levels [6]. However, Physiotherapists and Exercise professionals could intervene and rectify the running mechanism if the exercisers are found employing faulty running techniques (especially very high cadence due to apprehension while running on the treadmill). Despite longer lower limb lengths, some exercisers were found unable to run better than those with shorter lower limb lengths (Table 9). Biomechanical constraints like belowaverage flexibility of lower limb muscles and below-average muscular strength (especially Ectomorphic Endomorph body types) could severely affect the running economy and overall fitness standards. The importance of lower leg length to Running Economy (RE) will be most likely mediated through a more efficient running stride and the identification of the specific anthropometric variables that could characterize $\mathrm{RE}$ of distance runners is important and could be used for talent identification and performance prediction [7]. Physiotherapists can also investigate and prescribe suitable combination of cadence and step length apt for the stage of disease rehabilitation or exercise programs for sports, fat loss, healthy ageing etc. Such prescriptions could be based on manipulation of cadence for specific period of time to minimize the risks or maximize the performance of their clientele. After 6 weeks of cadence retraining (increasing running cadence by $10 \%$ ) carryover in kinematic and kinetic changes from an increased cadence state to a runner's preferred running cadence without decreased running efficiency was observed [8]. Physiotherapists should verify the variables responsible for the positive or negative outcomes of gait training (walking and running) to establish correlation with the therapy or training modalities or any other extraneous factors. In this study, some exercisers displayed similar step lengths in different speed levels. An example of unvarying step length as the speed increased is shown in Table 10. 
Table 9: Below-average fitness and running performance of Female B despite her normal BMI (19.2) was due to her Ectomorphic Endomorph somatotype with low muscularity. Female A and C, despite their high endomorphy were able to perform better because of their mesomorphy level. Inflexibility of muscles also could deter the running and jumping performance as seen in the characteristics of Female B. Ability to bend forward and touch the toes in sit and reach test is average whilst the ability to surpass the toe level or inability to touch the toes could be quantified with an inch tape to be expressed as above-average and below-average, respectively.

\begin{tabular}{|c|c|c|c|}
\hline & $\begin{array}{c}(\text { Female }- \text { A }) \\
\text { Age }=45 \\
\text { Height }=153 \mathrm{~cm} \\
\text { Weight }=66 \mathrm{Kg} \\
\text { Fat } \%=42 \\
\text { BMI }=28.2\end{array}$ & $\begin{array}{c}(\text { Female }- \text { B }) \\
\text { Age }=37 \\
\text { Height }=172 \mathrm{~cm} \\
\text { Weight }=57 \mathrm{Kg} \\
\text { Fat } \%=35 \\
\text { BMI }=19.2\end{array}$ & $\begin{array}{c}\text { (Female }- \text { C) } \\
\text { Age }=37 \\
\text { Height }=174 \mathrm{~cm} \\
\text { Weight }=73 \mathrm{Kg} \\
\text { Fat } \%=34 \\
\text { BMI }=24.1\end{array}$ \\
\hline Somatotype & $\begin{array}{c}\text { Mesomorphic } \\
\text { Endomorph } \\
10.5: 4.7: 0.27 \\
\end{array}$ & $\begin{array}{c}\text { Ectomorphic } \\
\text { Endomorph } \\
9.7: 1.4: 4.1 \\
\end{array}$ & $\begin{array}{l}\text { Mesomorphic } \\
\text { Endomorph } \\
10: 3: 2.2 \\
\end{array}$ \\
\hline Lower limb length & $78 \mathrm{~cm}$ & $92 \mathrm{~cm}$ & $94 \mathrm{~cm}$ \\
\hline Sit and reach score & $\begin{array}{c}+10 \mathrm{~cm} \\
\text { (Above average) }\end{array}$ & $\begin{array}{c}-\quad 30 \mathrm{~cm} \\
\text { (Below average) } \\
\end{array}$ & $0 \mathrm{~cm}$ (Average) \\
\hline Standing long jump & $120 \mathrm{~cm}$ & $100 \mathrm{~cm}$ & $155 \mathrm{~cm}$ \\
\hline $12 \mathrm{Km} / \mathrm{h}$ speed on Treadmill & $\begin{array}{l}\text { Able to withstand for } \\
30 \text { seconds maximum. } \\
(\mathrm{SLt}=106 \mathrm{~cm})\end{array}$ & $\begin{array}{l}\text { Unable to es tablish } \\
\text { biomechanical } \\
\text { stability and mental } \\
\text { confidence to run } \\
\text { beyond } 10 \mathrm{Km} / \mathrm{h} \text {. }\end{array}$ & $\begin{array}{l}\text { Able to withstand for } 1 \\
\text { minute } 30 \text { seconds. } \\
(S L t=113 \mathrm{~cm})\end{array}$ \\
\hline 28 meters Sprint in outdoor setting & $\begin{array}{c}15 \mathrm{Km} / \mathrm{h} \\
(\mathrm{SLo}=120 \mathrm{~cm})\end{array}$ & $\begin{array}{c}12.8 \mathrm{Km} / \mathrm{h} \\
(\mathrm{SLo}=120 \mathrm{~cm})\end{array}$ & $\begin{array}{c}16.5 \mathrm{Km} / \mathrm{h} \\
(\mathrm{SLo}=140 \mathrm{~cm})\end{array}$ \\
\hline
\end{tabular}

Table 10: 38 years old Male (38 years old male (Weight $=70 \mathrm{Kg}$, Height $=166 \mathrm{~cm}$, Fat $\%=32$, Lower limb length $=$ $83 \mathrm{~cm})$. He displayed similar step lengths while running at $15 \mathrm{Km} / \mathrm{h}$ on the treadmill and $18.6 \mathrm{Km} / \mathrm{h}$ in the outdoor setting. This is another example of individual-specific running strategy.

\begin{tabular}{|c|c|}
\hline Speed & Step length \\
\hline $\mathbf{1 2 . 5} \mathrm{Km} / \mathrm{h}$ (SLt) & $108.5 \mathrm{~cm}$ \\
\hline $\mathbf{1 5} \mathrm{Km} / \mathrm{h}$ (SLt) & $133 \mathrm{~cm}$ \\
\hline $\mathbf{1 8 . 6} \mathrm{Km} / \mathbf{h}$ (SLo) & $133 \mathrm{~cm}$ \\
\hline
\end{tabular}

Figure 2: Object $A$ must make 106 revolutions (10000 $\mathrm{cm} /(30 \mathrm{~cm} \times 3.14)$ to reach 100 meters. Object B must make $(10000 \mathrm{~cm} /(60 \mathrm{~cm} \times 3.14) 53$ revolutions to reach 100 meters. Based on their mechanical efficiency or the power applied, they could reach 100 meters in either equal speeds $(A=B)$ or differing speeds ( $A$ faster than $B$ or $B$ faster than $A)$.

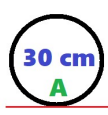

$100 \mathrm{~m}$

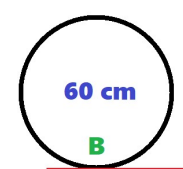

The increase of speed can be achieved by increased length or frequency of strides but the increase of both parameters simultaneously is quite difficult due to mutual dependency [9].
Suppose two circular objects of dissimilar sizes (Figure 2) and similar sizes (Figure 3) must roll over the ground and reach 100 meters, how many revolutions each must make and, can they differ in speeds based on the power applied?

Figure 3: Both the Object $A$ and $B$ must make $(10000 \mathrm{~cm}$ / $(60 \mathrm{~cm} \times 3.14) 53$ revolutions to reach 100 meters. Based on their mechanical efficiency or the power applied, they could reach 100 meters in either equal speeds $(A=B$ ) or differing speeds ( $A$ faster than $B$ or $B$ faster than $A)$.

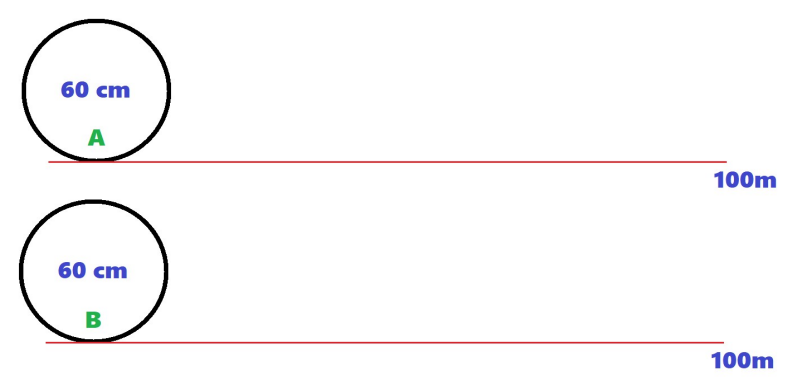

These examples of circular objects could be used as an analogy to understand the intra-individual and inter-individual variability in the cadence (number of revolutions made by the circular object in a given time and distance) and step length (distance travelled by the circular object per revolution) of walking and running. A school going boy $($ Age $=13$ years, Height $=149 \mathrm{~cm}$, 
Weight $=32 \mathrm{Kg}$, Lower limb length $=75 \mathrm{~cm}$ ) was able to perform 28 meters sprint at $20.3 \mathrm{Km} / \mathrm{h}$ with step lengths averaging $155 \mathrm{~cm}$, similar to or better than some men and women assessed in this study and this biomechanical efficiency is matching with the analogy that the smaller diameter objects (shorter lower limbs) could also perform equal to or better than the bigger diameter objects (longer lower limbs) if suitable power is applied/generated. In this study, the significant running speed exhibited by the exercisers in outdoor sprint tests indicates the limitations posed by treadmills on the exercisers because almost all of them felt the space on the treadmill inadequate, therefore not comfortable enough to challenge themselves at higher speeds available in the treadmill. But treadmills have other advantages when either outdoor running facilities are unavailable or the exercisers' deliberately wish to avoid outdoor exercises. It would be ideal whenever possible to schedule the training on both the treadmill and outdoor because majority of the exercisers readily incline to participate in the outdoor exercises if the climatic conditions are pleasant. From the perspective of assessments, treadmill could be more advantageous in collecting various data (speed, distance, time) easily to measure the physiologic variables like $\mathrm{VO}_{2 \text { max }}$.

Physiotherapists need not have to get confused if the walking or running performance of their clientele on the outdoor settings is significantly better than the treadmill performance. Training methods resulting in an improvement in Running Economy (RE) and $\mathrm{VO}_{2 \max }$ in treadmill tests would lead to a similar improvement in running on the track in high-level distance runners but $R E$ is significantly better on the track compared to the treadmill [10].

Competitive runners will occasionally undergo exercise in a laboratory setting to obtain predictive and prescriptive information regarding their performance and the lower RPE (Rate of Perceived Exertion) could be due to runners being more comfortable and familiar with over-ground compared to unfamiliar settings of treadmill running, especially when running at maximum speed [11]. This research has shown the simplest method to obtain the step length values by visually counting the walking and running cadence in both the treadmill and outdoor exercise settings. The continued increase in running popularity has led to a subsequent increase in the need to assess running gait more easily and affordably [12].

Collection of data on cadence and step length of personal clientele could be very useful for Physiotherapists for experiential learning, if not immediately for generalizations, to understand how the cohorts manipulate these two parameters of walking and running. The basic gait parameters most frequently used are velocity, step length, and step frequency and different investigators use varying units of measurement, further hampering comparisons [13]. To understand the biomechanical limitations of cadence and step lengths of non-athletic population, plenty of YouTube videos can also be viewed to study the running variables of well-trained runners and relate them with relevant research literatures. The very high step lengths and step rates achieved by elite sprinters may be possible only by a technique that involves a high horizontal and low vertical velocity of take-off, however, a greater vertical velocity of take-off might be of advantage when an athlete is fatigued and struggling to maintain a high step rate [14]. Usain bolt displayed a maximum stride length of 2.85 meters (Courtesy : YouTube Channel "The Way to Win" https://youtu.be/ PPbsJ-JogAg, viewed on 11.02.2020). Meticulous kinthropometric assessments have been vital in establishing linkage between the body structure with physical efficiency and more variables (like waist to hip ratio, cormic index, arm lengths, foot morphology) can be incorporated in the researches for understanding their correlations with cadence and step length of walking and running. High quality anthropometric measurements are fundamental to clinical and epidemiological research [15].

Physiotherapists and Exercise professionals can expect wide range of diversity in step length and cadence of individuals whose performance is chiefly regulated by the mesomorphy component of their somatotypes. Ectomorphic endomorph secures last rank as it is dominated by endomorphy with mesomorphy being the least [16]. It is a common contemporary outdoor 
exercise culture that lot of adults opt exclusively walking as their exercise (and no other exercise variations) regardless of the age which might not be facilitating healthy ageing. Preservation of various other biomechanical functions like multidirectional push and pull activities of upper extremities, squat, lunge, forward bending, jumping and particularly running should be the principal foundation goal for ageing without early onset of morbidities. Physiotherapists and Exercise professionals must encourage their clientele to engage in multiple strength and conditioning exercises targeting retention of or improvements in their running performance. The Running exercise seemingly protects against the worsening of both walking and running economy with advanced age and it may be that vigorous exercise, such as running, prevents the age-related deterioration of muscular efficiency in general, and therefore may make everyday activities easier [17].

The technology to accurately assess the step length and stride length are generally not available at clinical settings and fitness clubs in India, thus, the visual counting method discussed in this study could be convenient to probably get a near-accurate reading and the researchers also can try to combine this method with technologies that employ heel-marker data. The ability to calculate stride length for treadmill walking using heel-marker data may allow for quick and accurate gait calculations that further contribute to the versatility of heel data as a tool for gait analysis [18].

\section{CONCLUSION}

Assessment of cadence and step lengths of the patients and exercisers looks indispensable. Obtaining the cadence for one minute from the visually counted number of steps for 15 seconds looks feasible because higher running speeds associated with higher cadence would pose practical challenge to count the steps. Some experienced runners can be seen running comfortably at higher speeds nearing the upper limits in the treadmill for 200 to $\mathbf{4 0 0}$ meters and their running step length can also estimated by this indirect method. Focus should be equally on counting the number of steps looking at the foot placements, timer on the treadmill or stop clock and the status of exertion or fatigue of the exerciser, all coordinated at the same time by the Physiotherapist or Exercise professional. Proper instructions must be given to the exercisers to strictly avoid holding the rails of the treadmill during walking and running. SLt can also be obtained from counting the number of steps assigning some distance for walking and running (around 50 meters or 100 meters) and dividing the distance traveled by number of steps required to reach that distance. But the time-saving visual counting method to calculate the cadence can be easily acquired through practice, usually accompanied by the development of the skill to compute the step lengths using formula method. The same method can be used to ascertain and estimate the step lengths if the individuals are adapting symmetrical or asymmetrical step lengths by just separately counting the number of steps produced by each lower extremity for a specific time length ( 30 seconds or 60 seconds). Asymmetrical step lengths can be anticipated in patient population with different types of medical conditions (lower limb fracture, neurological impairment, prosthetic ambulation, asymmetrical flexibility of lower limb muscles).

Researches can be carried out using advanced technologies or in the gait laboratories to verify the level of accuracy of this innovative method both on the treadmill and outdoor settings. Scientists can also try to invent and incorporate technology in treadmills to pick up the signals from walking and running to display their cadence and step length on its monitor. Gathering data of individual-specific cadence and step lengths for different speeds can be used to track the impact of ageing process on these crucial variables by implementing longitudinal research design. Especially Physiotherapists who rely on their own exercise or rehabilitation units for their subsistence should also possess a treadmill as an integral diagnostic and therapeutic device and, without fail try estimating the step lengths of their clientele before and after the therapeutic interventions to evaluate the efficacy of the modalities opted for the rehabilitation. Though some treadmills offer higher speeds up to 23 $\mathrm{Km} / \mathrm{h}$ for training, the non-athlete population faces psychological constraints to comfortably 
run at higher speeds. It was also found that the non-athlete population were able to exhibit their maximum running speeds and step lengths on the ground in outdoor settings.

Based on the extensive data obtained from the non-athletes and athletes (it might take several months or years to collect that amount of data on large sample size for different walking and running speeds), it is also possible to construct a 'cadence versus step length table' for quick reference to get general information about human locomotion and specific information pertinent to various disease and disease rehabilitation programs, sports performance, structured fitness training and the effects of ageing.

\section{Conflicts of interest: None}

\section{REFERENCES}

[1]. R. Vinodh Rajkumar. Prevalence of Outward Deviation of Feet in Human Gait: A Non-Participant Observation. Int J Physiother Res 2020;8(1):3378-3387.

[2]. Amy G. Schubert, Jenny Kempf, Bryan C. Heiderscheit. Influence of Stride Frequency and Length on Running Mechanics. Sports Health. 2014; 6(3): 210-217.

[3]. Heiderscheit, Bryan C.; Chumanov, Elizabeth S; Michalski, Max P; Wille, Christa M; Ryan, Michael B. Effects of Step Rate Manipulation on Joint Mechanics during Running. Medicine \& Science in Sports \& Exercise. 2011: 43 (2):296-302.

[4]. Holden, M.K., Gill, K.M., \& Magliozzi, M.R. Clinical gait assessment in the neurologically impaired: Reliability and meaningfulness. Physical Therapy, 1984; 64:35-40.

[5]. Iain Hunter, Kelly Leee, Jared Ward, James Tracy. Self-optimization of stride length among experienced and inexperienced runners. Int J Exerc Sci. 2017; 10(3): 446-453.

[6]. Salo Al, Bezodis IN, Batterham AM, Kerwin DG. Elite sprinting: are athletes individually step-frequency or step-length reliant? Med Sci Sports Exerc. 2011;43(6):1055-62.

[7]. Rauno Laumets, Karel Viigipuu, Kerli Mooses, Jarek Mäestu, Priit Purge, Ando Pehme, Priit Kaasik, Martin Mooses. Lower Leg Length is Associated with Running Economy in High Level Caucasian Distance Runners. J Hum Kinet. 2017; 56: 229-239.
[8]. Jocelyn F. Hafer, Allison M. Brown, Polly deMille, Howard J. Hillstrom, Carol Ewing Garber. The effect of a cadence retraining protocol on running biomechanics and efficiency: a pilot study, Journal of Sports Sciences. 2015; 33 (7), 724-731.

[9]. MacKala Krzysztof, Antti Mero. A Kinematics Analysis Of Three Best $100 \mathrm{M}$ Performances Ever. J Hum Kinet. 2013; 36: 149-160.

[10]. M Mooses, B Tippi, K Mooses, J Durussel, J Mäestu. Better economy in field running than on the treadmill: Evidence from high-level distance runners. Biol Sport. 2015; 32(2): 155-159.

[11]. Mugele $H$, Plummer A, Baritello O, Towe $M$, Brecht $P$, et al. (2018) Accuracy of training recommendations based on a treadmill multistage incremental exercise test. PLOS ONE. 2018;13(10): e0204696.

[12]. Higginson, Brian K. Methods of Running Gait Analysis. Current Sports Medicine Reports. 2009; 8(3):136-141.

[13]. J Tommy Oberg, Alek Karsznia, Kurt Oberg. Basic gait parameters: Reference data for normal subjects, 10-79 years of age. Journal of Rehabilitation Research and Development. 1993; 30(2):210-223.

[14]. Hunter, J. P., R. N. Marshall, and P. J. McNair. Interaction of Step Length and Step Rate during Sprint Running. Med. Sci. Sports Exerc. 2004: 36 (2), 261-271.

[15]. Mony PK, Swaminathan S, Gajendran JK, Vaz M. Quality assurance for accuracy of anthropometric measurements in clinical and epidemiological studies [Errare humanum est $=$ to err is human]. Indian J Community Med 2016;41:98-102.

[16]. R. Vinodh Rajkumar, Endomorphy dominance among non-athlete population in all the ranges of Body Mass Index. Int J Physiother Res. 2015;3(3):10681074.

[17]. Beck ON, Kipp S, Roby JM, Grabowski AM, Kram R, Ortega JD. Older Runners Retain Youthful Running Economy despite Biomechanical Differences. Med Sci Sports Exerc. 2016;48(4):697-704.

[18]. Kevin Supakkul, Using Positional Heel-marker Data to More Accurately Calculate Stride Length for Treadmill Walking: A Step Length Approach. 2017. arXiv:1710.09030v1 [q-bio.QM].

How to cite this article:

R. Vinodh Rajkumar. INDIRECT ESTIMATION OF THE STEP LENGTH OF WALKING AND RUNNING PERFORMANCES ON THE TREADMILL. Int J Physiother Res 2020;8(2):3407-3414. DOI: 10.16965/ijpr.2020.110 